\title{
An Innovative Preschool Education Method Based on Computer Multimedia Technology
}

\author{
https://doi.org/10.3991/ijet.v14i14.10714 \\ Xiaoyue Wang $(\bowtie)$ \\ Shijiazhuang Preschool Teachers College, Shijiazhuang, China \\ 34406082 @qq. com \\ Han Sun \\ Shi Jiazhuang Division of PLAA Infantry College, Shijiazhuang, China \\ Lixin $\mathrm{Li}$ \\ Shijiazhuang Preschool Teachers College, Shijiazhuang, China
}

\begin{abstract}
Hybrid learning is the fruit of deep integration between computer multimedia technology and the Internet technology. This learning method has attracted much attention in the academia, as it enriches the teaching resources, improves the flexibility of learning time and enhances the teacher-student interaction. This paper attempts to develop on innovative preschool education method based on computer multimedia technology. For this purpose, the popular intelligent teaching platform was introduced to construct a hybrid teaching mode based on the Rain Classroom (RC). Then, it applied this mode to the teaching of the course Modern Educational Technology, and evaluated the application effect through questionnaire survey. The results show that this hybrid teaching method is suitable for the students, and capable of improving their learning interest and overall ability. The research provides new theoretical and practical results of preschool education teaching, and promotes the reform of preschool education.
\end{abstract}

Keywords - Rain classroom (RC), hybrid teaching, computer multimedia technology, innovative preschool education method

\section{$1 \quad$ Introduction}

Preschool education is an important part of the national education system and the beginning of lifelong learning. As people attach more importance to their children's education, the preschool education profession has also received great attention from the society. The rapid development of computer multimedia technology and Internet information technology has greatly benefited the education field. The "Internet + education" model is the development trend of information-based education reform [1]. In this context, in order to cultivate pre-school professional teachers meeting the social needs, it is imperative to carry out the innovation of preschool education model based on advanced computer multimedia technology and Internet technology. 
The study of E-learning originated from a paper in the Training Magazine of American in 1996 [2]. But because the effect of e-learning is not ideal, the blended learning was then proposed, that is, combining traditional teaching with online teaching to fully reflect the dominant position of students [3]. Jennifer Hofmann believes that the essence of blended learning is mixing and rationally applying various media resources to the corresponding teaching process [4]. Reid Carmen thinks that the online and offline interaction of the teacher and students is the most important part of blended learning [5]. Some other scholars state that blended learning can cultivate the students' cooperative ability and communication skills while enhancing their knowledge level [6]. In China, the research on blended learning was firstly conducted by Professor He Kehang in 2003. Li Kedong believes that the key part of blended learning lies in the selection of information transmission channels [7]. Xiao Shicheng proposed that high quality learning resources and a sound learning platform are the important foundation for blended learning [8]. Guqin divided blended learning into three stages: pre-analysis, online learning, offline communication, and improvement [9]. With the popularity of smart phones, QQ, Weibo and WeChat have become the main tools for communication among contemporary college students. The mobile learning mode has become a new generation of learning method [10]. In this context, various universities and enterprises have launched a variety of smart learning applications, especially, "Ketangpai ", "Google Classroom", "Rain Classroom" etc. have been studied and applied in different universities [11]. Among them, "Rain Classroom" is widely accepted and used because of its rich content, versatility and free use [12].

Based on the above analysis, this paper attempts to combine the RC with the traditional teaching method, and study the innovative preschool education method based on computer multimedia technology. It constructs a RC-based hybrid teaching mode, to analyse the main activities of teachers and students before class, in class and after class in detail. Finally, taking the course Modern Educational Technology of preschool education profession as an example, the application of this teaching mode in preschool education was studied.

\section{Basic Survey on Hybrid Teaching Based on Rain Classroom}

\subsection{Introduction to rain classroom}

RC was launched jointly by Tsinghua University's Online Education Office and XuetangX in June 2016 [13]. The RC is a plug-in for PowerPoint, which uses technical information approach to realize the seamless linking between WeChat and PowerPoint through QR codes scanning. It can provide students with a personalized learning environment, in which the students can learn anywhere and anytime online by WeChat, and then track and analyse their learning [14]. 


\subsection{The basic situation for hybrid teaching based on the rain classroom}

To study the feasibility of the RC-based hybrid teaching mode in preschool education profession, this paper selects 163 pre-school education professional students from 5 classes of one university in Shandong Province. The survey questionnaires on the hybrid teaching were issued to these students, and 157 questionnaires were recovered with an effective rate of $96.32 \%$. The specific results are as follows:

Basic survey: Figure 1 shows that the students surveyed are registered and have their own WeChat accounts, where 98.6\% said they often use WeChat, for more than 4 hours per day, and $1.4 \%$ students rarely use it although they have a WeChat account. In the survey on whether to follow and use the WeChat official account, $99.1 \%$ of the students indicated that they would obtain knowledge or related information by the WeChat official account.

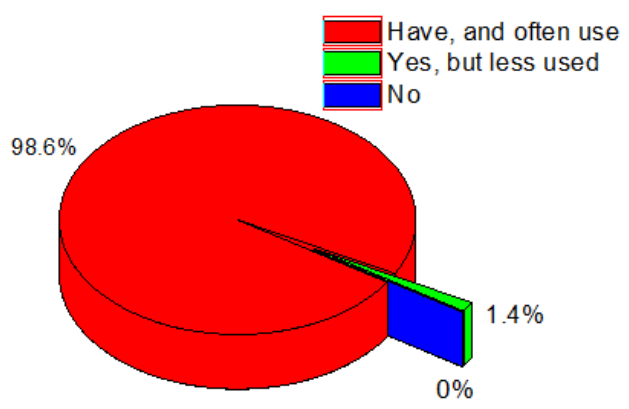

Fig. 1. WeChat usage

\section{Cognition of hybrid learning}

Understanding of hybrid learning: Figure 2 shows the survey results for the students' understanding of the hybrid learning. It can be seen from the figure that $48.47 \%$ of the students said that they did not understand the hybrid learning, while only $11.2 \%$ understood about it, indicating that the current education received by students still follows the traditional mode of teacher teaching and student learning.

The way students like to learn: Figure 3 shows the survey results of the learning way that students like. It can be seen from the figure that most students have become accustomed to the teacher-dominated teaching methods in the classroom, but there are still more than half of the students who is willing to learn online through online discussions, group-based collaborative learning, or their own self-study practices. 


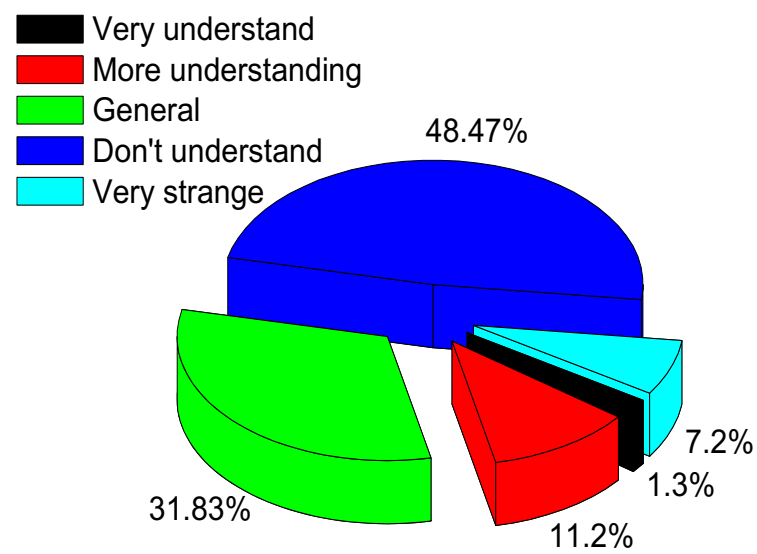

Fig. 2. Students' understanding of hybrid learning

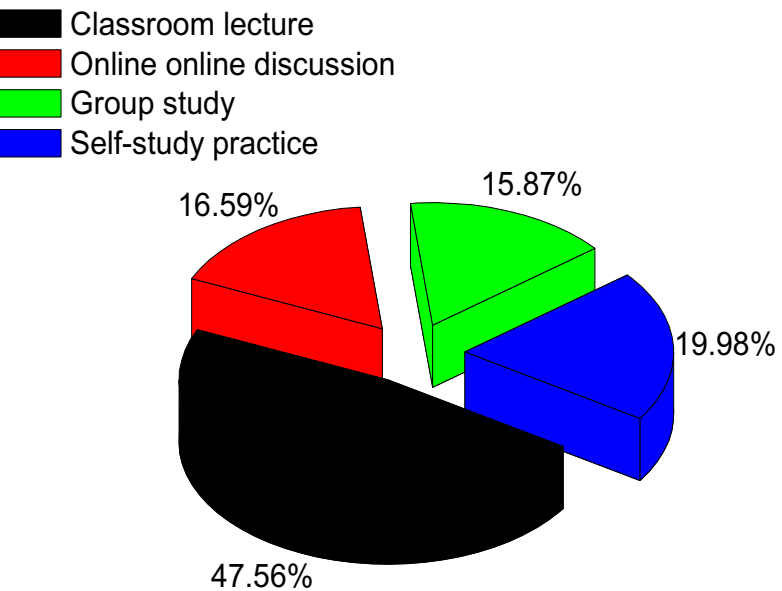

Fig. 3. The way students like to learn

The survey results show that students have the material basis for learning in the $\mathrm{RC}$; although students are more accustomed to traditional classroom teaching, most students are interested in other teaching methods and self-study, indicating that it is feasible to use the RC for hybrid teaching.

\section{Application Research of Rain Classroom-Based Hybrid Teaching in Preschool Education Profession}

\subsection{Course analysis}

Education informatization is China's basic national policy, for which the educational information technology should be integrated into teaching activities. 
Therefore, Education Informational Technology is already a compulsory public course for normal colleges in China. This course can train students to enrich teaching methods, innovate teaching resource design forms, improve self-information literacy, and help them break the teaching bottleneck in their future teaching work. However, as a public course, Educational Informational Technology is mostly taught in large classes. In such classroom, the teacher is dominated, but easily ignoring the needs of each student, and there is little interaction time between teachers and students, so that students have low learning interests in the course, and most of them just review the course before the exam. Furthermore, the teaching objectives of this course are difficult to achieve, and the teaching effect of the course is not ideal. Therefore, this paper attempts to redesign the teaching mode by using the hybrid teaching mode based on the RC, in order to improve the teaching effect.

\subsection{Design and implementation of Rain classroom-based hybrid teaching mode}

The RC-based hybrid teaching requires a computer network room with the teacher's computer and student's computer. In addition, the teacher and the students all should have a smart phone, and follow the official account of RC [15]. In order to make the whole learning process reasonable, effective and smooth, this paper divides this hybrid teaching mode into three stages: pre-class, in-class and after-class [16], as shown in Figure 4.

\begin{tabular}{|c|c|c|}
\hline $\begin{array}{l}\text { After } \\
\text { class }\end{array}$ & $\begin{array}{l}\text { Teacher activity } \\
\text { 1、 Materials } \\
\text { 2、 Resource release } \\
\text { 3、Teaching plan }\end{array}$ & $\begin{array}{l}\text { Student Activities } \\
\text { 1、 Self-study } \\
\text { 2、 Online chating } \\
\text { 3、 Learning experience }\end{array}$ \\
\hline $\begin{array}{l}\text { In } \\
\text { class }\end{array}$ & $\begin{array}{l}\text { Teacher activity } \\
\text { 1、Identify the problem } \\
\text { 2、Create a situation } \\
\text { 3、 Multi-screen } \\
\text { teaching } \\
\text { 4、Arranging new tasks } \\
\text { 5、Classroom test } \\
\text { 6. Real time review }\end{array}$ & $\begin{array}{l}\text { Student Activities } \\
\text { 1、Organizing problems } \\
\text { 2、 Multi-screen learning } \\
\text { 3、Cooperation and exchange } \\
\text { 4、Submit within a limited } \\
\text { time } \\
\text { 5、Consolidate internalization }\end{array}$ \\
\hline $\begin{array}{l}\text { After } \\
\text { class }\end{array}$ & $\begin{array}{l}\text { Teacher activity } \\
\text { 1、 Making targeted } \\
\text { exercises } \\
\text { 2、Personalized } \\
\text { counseling }\end{array}$ & $\begin{array}{l}\text { Student Activities } \\
\text { 1、Complete the problem } \\
\text { 2、 Summary reflection }\end{array}$ \\
\hline
\end{tabular}

Fig. 4. Design of hybrid teaching mode in rain classroom 


\section{Pre-class preparation stage}

Teacher activities: Before class, teachers need to download and install the computer version of RC on the computer, and log in by the scanning the QR code in WeChat. They create courses, classes, courseware, exercises, and test questions through the PPT RC function on the computer. The RC also supports the pluggable MOOC videos and network videos. Figure 5 shows the RC interface, in which the teacher can push the prepared learning resources to the students through WeChat, or display the pre-study materials through the network video connection. Figure 6 shows the share link interface; after issuing the relevant tasks, the teacher can specify the learning tasks through the voice function, thereby facilitating the students' learning. Teachers can also check the details of the students' pre-study by clicking "view details", answer the questions encountered by the students in time, and adjust the teaching methods in a targeted manner; Figure 7 shows that the teacher can view the students' pre-class preparation through the RC in the mobile phone.

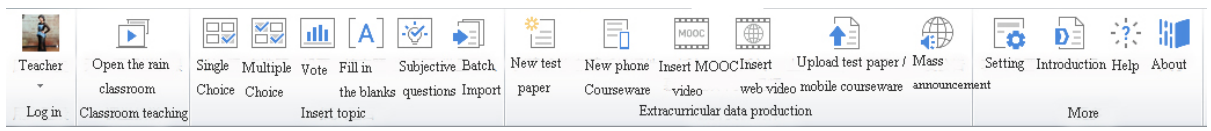

Fig. 5. Rain classroom interface

Chapter 1 Introduction to Modern Educational Technology

http://www.tudou.com/home/_739826930/item

If there is a problem with your phone, please check it out on this website.

\section{Add another $\quad$ Preview}

Fig. 6. Share link interface 


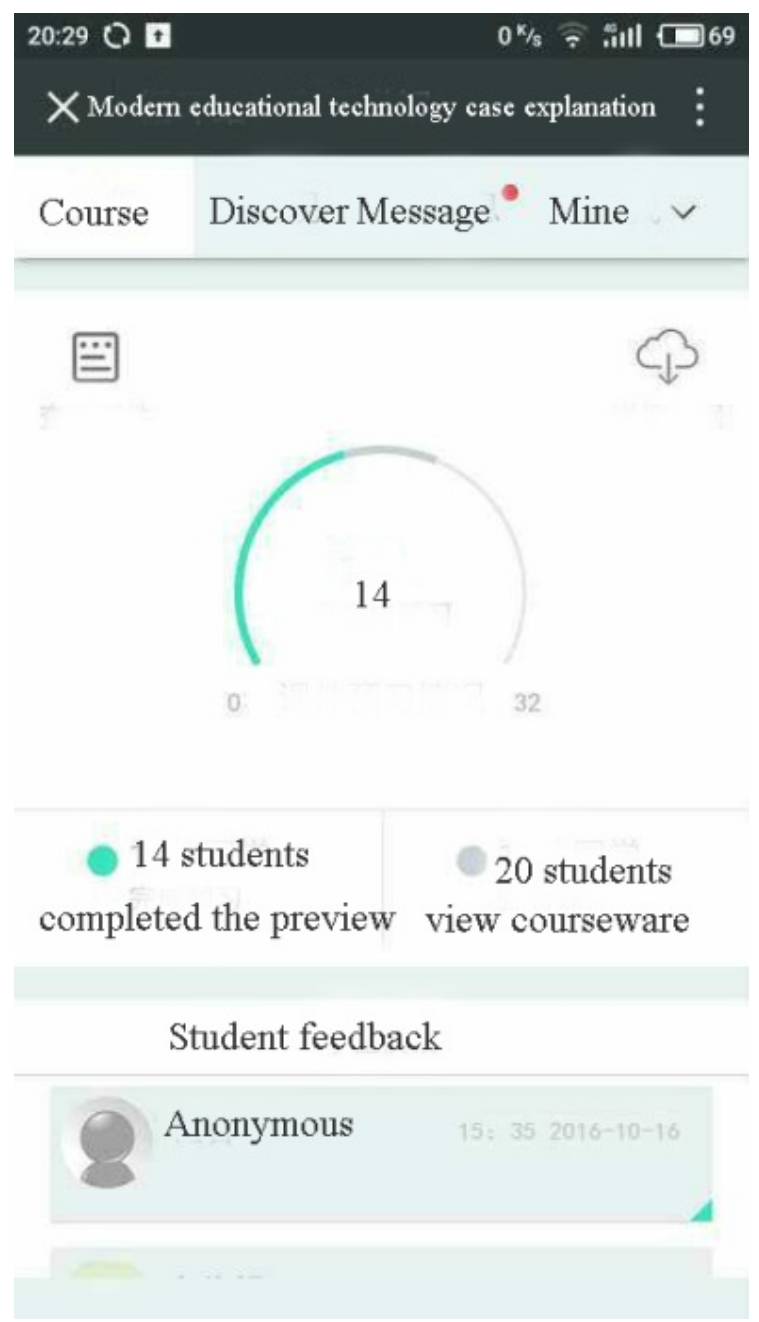

Fig. 7. Student preparation statistics

Student activities: Only by following the official account of RC through WeChat, and inputting the class invitation code sent by the teacher, the students can receive the push reminder sent by the system, and learn in time. When problems are encountered during the learning process, the students can raise these questions in the question bar, or mark the PPT that they don't understand. All these shall be fed back to the teacher. Figure 8 shows the student's feedback to the teacher about these problems. 


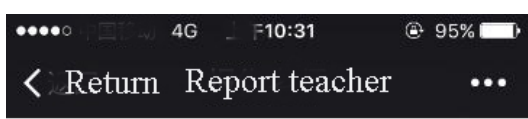

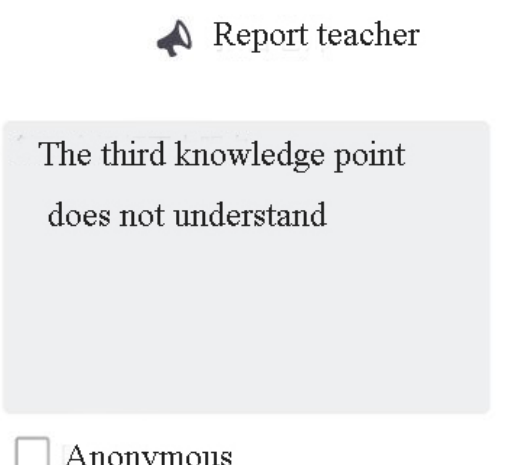

\section{Confirm send}

Fig. 8. Feedback learning problem

\section{In-class learning activities stage}

Teacher activities: The teachers judge the students' pre-study situation according to the questions submitted by the students, highlight the key points in class, create the teaching situation, and introduce the course through the test and preview feedback. They log into the RC through the teacher computer, projector and mobile phone. As shown in Figure 9, the teacher scans the QR code of the mobile phone to log in the $\mathrm{RC}$ on the computer, and displays the classroom content through the projector. Besides, the big data function of RC can be used to make real-time statistics of the students' thoughts on learning problems in real time, then to present the results to the students through the projector for discussion and study, and send the test questions to them after class for understanding their learning situation in class.

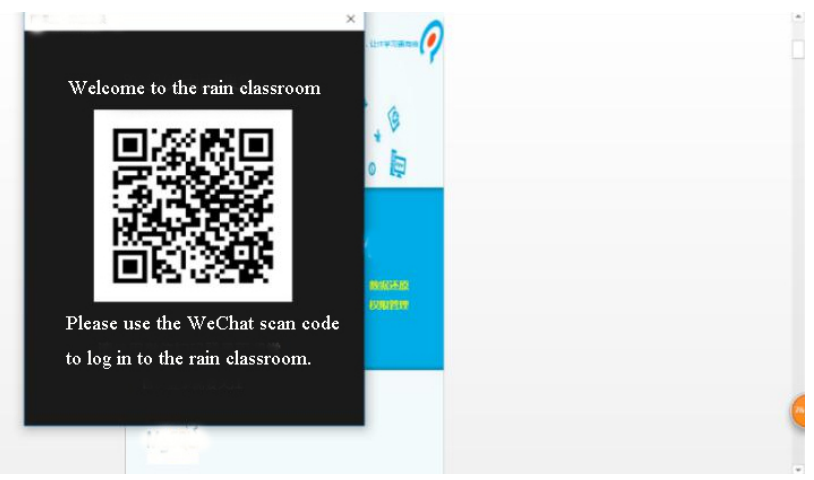

Fig. 9. Scan and $\log$ in to the computer side rain classroom 
Student activities: In class, the students make discussions and exchanges by groups. Afterwards the resolved and unsolved problems of the group are reported to the teacher through the mobile device. Students can also use the mobile phone terminal to complete the teacher's regular test and ask questions according to the teacher's explanation. The question will be displayed through the "bullet screen" function of the $\mathrm{RC}$ for the discussion of teachers and students.

\section{After-class personalized guidance stage}

Teacher activities: The teachers arrange homework according to the students' inclass learning, prepare targeted exercises for them, and help them to consolidate the knowledge acquired in the class. They also provide students with personalized guidance according to the students' homework and test completion status as well as the questions submitted by the students.

Student activities: The students complete the assignments, exercises and other related learning tasks by the teacher, find out their own deficiencies in the learning, communicate with the teachers, make summarization and reflection according to the teachers' guidance and evaluation given, and thus consolidate and internalize the knowledge.

\subsection{Application effect of hybrid teaching based on rain classroom in preschool education profession}

In this paper, the questionnaire survey was used to investigate the learning situation of 163 students from 5 classes of the pre-school education profession in one university of Shandong province. The course Modern Educational Technology was selected using the RC. The specific results are as follows:

Survey on students' adaption to the hybrid teaching mode: Figure 10 shows the survey results of the student's adaption to hybrid teaching mode based on the RC. It can be seen from the figure that only $15.32 \%$ of the students expressed that they did not adapt to this learning mode, and most students could adapt to this, indicating that modern college students have strong adaptability and can accept new teaching modes.

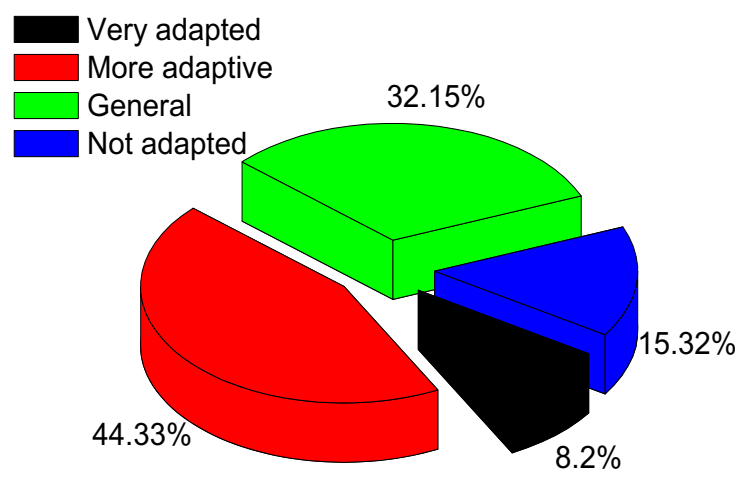

Fig. 10.Adaptation survey results 
Survey on learning effects: Figure 11 shows the results of the survey on the learning effects in the RC-based teaching mode. It can be seen from the figure that about $45 \%$ of the students think that the RC teaching mode can help to improve their interest in learning; most students believe that this mode can improve their ability of self-learning, analysis and problem-solving, and deepen their mastery of basic knowledge and modern educational technology knowledge.

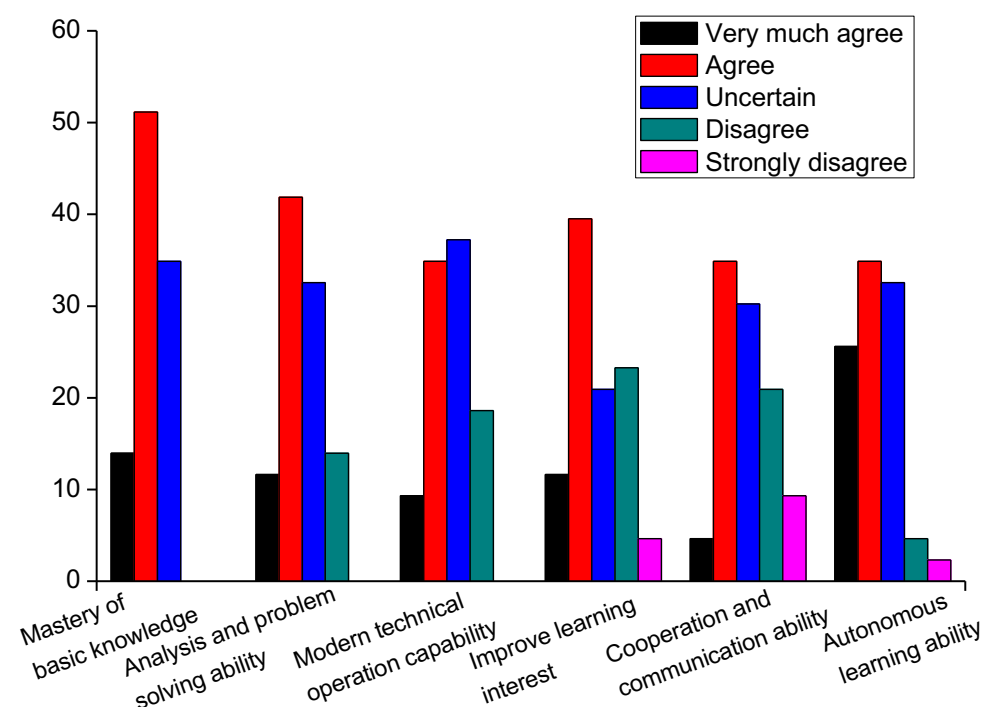

Fig. 11.Learning effect survey results

\section{Conclusion}

The integration of information technology, Internet technology with education has promoted the reform of informationization in the field of education. This paper attempts to study the innovative methods of preschool education based on computer multimedia technology. The specific conclusions are as follows:

- The RC was firstly introduced in brief. Then, the survey questionnaire was conducted to investigate the application basis of RC in the preschool education profession. The results show that the preschool education profession has the material basis for the hybrid teaching in $\mathrm{RC}$, and the students has certain expectations for this teaching mode.

- Taking a public course Modern Educational Technology of the preschool education profession as an example, the RC-based hybrid teaching mode was designed, and the tasks of teachers and students in each link were also analysed in detail.

- The application effect of the RC-based hybrid teaching mode in the Modern Educational Technology course was analysed. The results show that most students 
can accept this teaching mode, and this mode can improve students' learning interest and comprehensive ability.

\section{Acknowledgement}

This study is a research School-level topic of Shijiazhuang Preschool Teachers College. The topic number is KY-201838 and the topic name is Study on Training Research on the Application of Rain Classroom in Pre-school Education. The responsible person for the topic: Xiaoyue Wang.

\section{References}

[1] Clark, E. (2012). Innovation and its contribution to the scholarship of learning and teaching. Nurse Education Today, 32(7): 729-731. https://doi.org/10.10 16/j.nedt.2012.06.001

[2] Lester, J. C., Stone, B. A., Stelling, G. D. (1999). Lifelike pedagogical agents for mixedinitiative problem solving in constructivist learning environments. User Modeling and User-Adapted Interaction, 9(1-2): 185-228. https://doi.org/10.1007/978-94-017-1118-0 5

[3] Huang, E. Y., Lin, S. W., Huang, T. K. (2012). What type of learning style leads to online participation in the mixed-mode e-learning environment? a study of software usage instruction. Computers \& Education, 58(1): 338-349. https://doi.org/10.1016/j.co mpedu.2011.08.003

[4] Yuan, S. T., Chang, W. L. (2001). Mixed-initiative synthesized learning approach for webbased crm. Expert Systems with Applications, 20(2): 187-200. https://doi.org/10.1016/s0957-4174(00)00058-0

[5] Porter, W. W., Graham, C. R., Spring, K. A., Welch, K. R. (2014). Blended learning in higher education: institutional adoption and implementation. Computers \& Education, 75: 185-195. https://doi.org/10.1016/j.compedu.2014.02.011

[6] Victoria López-Pérez, M. Carmen Pérez-López, M. \& Rodríguez-Ariza, L. (2011). Blended learning in higher education: students' perceptions and their relation to outcomes. Computers \& Education, 56(3): 818-826. https://doi.org/10.1016/i.compedu.2010.10.023

[7] Neumeier, P. (2005). A closer look at blended learning — parameters for designing a blended learning environment for language teaching and learning. ReCALL, 17(02): 163178. https://doi.org/10.1017/s0958344005000224

[8] Ryan, S., Grieshaber, S. J. (2005). Shifting from developmental to postmodern practices in early childhood teacher education. Journal of Teacher Education, 56(1): 34-45. https://doi.org/10.1177/0022487104272057

[9] Hsiao, H. S., \& Chen, J. C. (2016). Using a gesture interactive game-based learning approach to improve preschool children।"s learning performance and motor skills. Computers \& Education, 95: 151-162. https://doi.org/10.1016/j.compedu.2016.01.005

[10] Oliver, M. E., Butler, L. G., Cordes, A. W. (1995). Learning the student names in large classes: an application of multimedia technology. Journal of Chemical Education, 72(7): 610. https://doi.org/10.1021/ed072p610

[11] Elsherbeni, A., Tew, M., \& Mokaddem, A. (2014). Applying multimedia technology to undergraduate engineering laboratories. Computer Applications in Engineering Education, 3(3): 157-164. https://doi.org/10.1002/cae.6180030303

[12] SuárezOrozco, C, Casanova, S., Martin, M., Katsiaficas, D., Cuellar, V., \& Smith, N. (2015). Toxic rain in class. Educational Researcher, 44(3): 151-160. https://doi.org/10.31 02/0013189x15580314

[13] Friedland, G., \& Pauls, K. (2005). Architecting multimedia environments for teaching. Computer, 38(6): 57-64. https://doi.org/10.1109/mc.2005.181 
[14] Liu, H., Li, Q., \& Han, H. (2012). Innovation and practice of the teaching monitoring method for the digital media technology programme. International Journal of Continuing Engineering Education and Life-Long Learning, 22(3/4): 226. https://doi.org/10.1504/ijceell.2012.050067

[15] Magnuson, K. A., Meyers, M. K., \& Waldfogel, R. J. (2004). Inequality in preschool education and school readiness. American Educational Research Journal, 41(1): 115-157. https://doi.org/10.3102/00028312041001115

[16] Schwartz, I. S., \& Carta, J. J. (1996). Examining the use of recommended language intervention practices in early childhood special. Topics in Early Childhood Special Education, 16(2): 251-272. https://doi.org/10.1177/027112149601600208

\section{$7 \quad$ Authors}

Xiaoyue Wang received a master's degree in pedagogy in 2009 from Southwest University, Chongqing, China. She majors in the preschool education, and her research focus on early education and preschool teacher training. She has been working at Shijiazhuang Preschool Teachers College.

Han Sun received the B.S. degree in Computer Science and Technology in 2006 from Nankai University, Tianjin, China. He has been on the faculty of The Army Infantry Academy of PLA since 2008. He has been a cisco certified network associate (CCNA) since 2012.His research interests include network technology and educational technology.

Lixin Li Professor received the B.S. degree of pedagogy in 1987 and then a master's degree of Education management in 2009 from Hebei Normal University, Shijiazhuang, Hebei, China. He currently works at Shijiazhuang Preschool Teachers College as a professor and head of the faculty of preschool education. His current research direction is teacher education.

Article submitted 2019-04-13. Resubmitted 2019-05-27. Final acceptance 2019-05-27. Final version published as submitted by the authors. 